\title{
Sound Absorption and Friction Properties of Nano-Lotus Leaf Coated Concrete for Rigid Pavement
}

\author{
Marcelo GONZALEZ ${ }^{1 *}$, Md SAFIUDDIN ${ }^{2}$, Jingwen $\mathrm{CAO}^{3}$, Susan $_{\text {TIGHE }}^{3}$ \\ ${ }^{1}$ Department of Construction Engineering and Management, Pontificia Universidad Católica de Chile, Vicuña Mackenna \\ 4860 Edificio San Agustin Piso 3 Santiago, Chile 7820436 \\ ${ }^{2}$ School of Architectural Studies and Angelo del Zotto School of Construction Management, George Brown College, 146 \\ Kendal Avenue, Toronto, Ontario, Canada M5T 2 T9 \\ ${ }^{3}$ Department of Civil and Environmental Engineering, University of Waterloo, 200 University Avenue West, Waterloo, \\ Ontario, Canada N2L $3 G 1$
}

cross $^{\text {ref }}$ http://dx.doi.org/10.5755/j01.ms.22.3.7638

Received 2July 2014; accepted 15 July 2015

\begin{abstract}
This paper presents the feasibility of superhydrophobic films to create the nano-lotus leaf effect on concrete surface and their influence on sound absorption and friction properties of concrete for application in rigid pavements. The study involved an evaluation of nanomaterials at the laboratory scale to analyze the effects of microtexture modification on the friction and sound absorption of concrete pavement. A number of laboratory specimens were produced by applying different amounts of nano-lotus leaf coating on the top of the textured concrete surface. The British pendulum test was used to measure the friction number, and an impedance tube was used to determine the sound absorption coefficient Laboratory results indicate that nano-lotus leaf coated concrete can maintain the required friction property for rigid pavement, but may not increase the noise absorption. Further research must be carried out to determine possible benefit of the lotus leaf effect for reducing hydroplaning, particularly during heavy rainfall.

Keywords: friction, lotus leaf, microtexture, nanotechnology, sound absorption.
\end{abstract}

\section{INTRODUCTION}

Friction and sound absorption are two functional properties of concrete or rigid pavement; these two properties are important for ensuring traffic safety. Rigid pavements are conventionally textured using a burlap drag process. However, because this texturing method does not provide a minimum frictional coefficient of 0.30 , the other texturing methods have been developed to improve frictional/safety characteristics of rigid pavements; the most common is the transversal tinning method $[1,2]$. These new alternatives of finishing provide water drainage and improve the macrotexture of the concrete surface, resulting in an increased friction between tire and pavement. However, as the traffic volume increases, the vehicle noise emission becomes a concern due to the pavement-tire interaction $[1,2]$. In pavements, a higher sound absorption coefficient of the surface material results in a lesser noise emission.

Vehicle noise has required the investment of billions of dollars in noise barriers to mitigate the noise impact. Also, according to Scofield [3], many efforts have concentrated on reducing noise production at the source, which is the interaction between pavement and tire. Consequently, Next Generation Concrete Surface (NGCS) has evolved as a new concrete pavement texture in the United States; NGCS has the quietest surface texture developed for conventional concrete pavement, mainly through the modification of macrotexture [3].

Due to the importance of noise emission and friction in rigid pavements, some attempts have been taken based on

\footnotetext{
${ }^{*}$ Corresponding author. Tel.: 56-2-2354-4244.

E-mail address: magonza7@ing.puc.cl (M. Gonzalez)
}

nanotechnology to study how these two properties are influenced by the modification of microtexture in concrete surface. According to Gonzalez et al. [4], nanosilica can improve the noise absorption and friction properties of concrete due to a modification of microstructure. According to Button et al. [5], lotus leaf exhibits an exceptional ability to keep its surface clean and dry through very high water repellence. Therefore, nano-lotus leaf products can be used to create a self-cleaning coating on concrete pavement.

Nanotechnology deals with the "boundary between atoms and molecules and the macro world, where ultimately the properties are dictated by the fundamental behaviour of atoms" [6]. If nanotechnology can be applied with novelty, a revolutionary change may be possible in terms of material performance and new applications in concrete pavement.

The knowledge of nanotechnology has been applied in the present study to investigate the effects of nano-lotus leaf coating on the sound absorption and friction properties of concrete pavement. This study was also carried out to evaluate whether nano-lotus leaf coating can be applied on concrete surface, while maintaining the required friction and sound absorption properties of rigid pavement. Laboratory results revealed that nano-lotus leaf coating can maintain the required friction property for concrete or rigid pavements. However, test results indicate that such coating may not increase the noise absorption of rigid pavements.

\section{LITERATURE REVIEW}

\subsection{Nanotechnology}

Nanotechnology has been developed based on the application of basic physics, chemistry, and biology at the 
particle size range of a few nanometers to submicron dimensions. At the nanometer scale, many macroscopic properties of a material change, allowing the material to perform differently in various applications [7-10]. Nanotechnology involves the 'bottom-up' approach to create nano-composites by modifying organic and inorganic structures with molecular assemblages, aggregates and fibers, chemical bonds, intermolecular forces and intraphase diffusion [7, 9, 11].

The recent research in construction technology focuses the application of nanotechnology on cement-based materials $[11,12]$, thus developing the concept of nanoconcrete. A concrete including portland cement particles with an average size $<500$ nanometer is defined as nanoconcrete [12]. The most important reason to apply nanotechnology in concrete is to control material behaviour, provide superior mechanical performance, and add novel properties such as self-sensing, self-cleaning and self-healing capabilities, high ductility, and self-control of cracks [11].

\subsection{Nano-lotus fundamentals and hydrophobic effect}

In recent years, the use of lotus fundamentals and hydrophobic effect has received growing attention all over the world. Current research has indicated that the lotus leaf possesses some self-cleaning properties. The lotus effect contributes to non-wetting, super water repellent, and super hydrophobic surfaces and thus enhances self-cleaning properties [13-16].

The self-cleaning properties are believed to be related to the special surface structure and low free surface energy [14-16]. The waxiness (greasiness) also provides a hydrophobic surface. The contact angle between water droplet and surface usually remains at $<30^{\circ}$ for most of the hydrophilic surface [17]. However, for a hydrophobic surface, the contact angle can increase to $>90^{\circ}$ [17], thus decreasing the contact area of water droplet with the surface. The minimization of the contact area between water droplet and leaf surface causes water droplets to easily roll off the leaf $[14,17]$. This phenomenon is well known as the 'lotus effect'.

The super hydrophobicity of a surface does not only result from its waxiness, but also depends on the microstructure and nanostructure of the surface [14-17]. The combination of microstructure and nanostructure causes the contact angle to exceed $150^{\circ}$ and the sliding angle to be $<10^{\circ}[15-17]$. The double-scale structure contains micro-bumps that are 5 to $9 \mu \mathrm{m}$ in diameter, nano-branches on the micro-bumps, and the area between every two bumps that are around $124 \mathrm{~nm}$ in diameter [16]. In this case, water forms spherical droplets on the leaf surface with very little contact area, that is, very high contact angle [17]. Indeed, the contact angle continues to increase due to the air trapped between water droplet and leaf surface [17].

\subsection{Hydrophobic effect and frictional response}

The use of a lotus leaf coating is suggested for creating the self-cleaning capability in rigid pavements [5]. However, the frictional response of pavement must be carefully evaluated. According to Ashby et al. [6], nano- surfaces with lotus effect have special roughness characteristics that produce a reduction in the contact area. The reduction in the contact area may decrease the friction property of pavement. Yet, the hydrophobic effect of lotus leaf could be beneficial in areas with heavy rainfall because it helps to quickly remove the water from the surface.

The water film thickness is also a critical factor for rigid pavements, particularly for the safety during driving, because it affects the friction between tire and concrete surface. At high speed, the water film thickness is crucial for frictional response due to the lubrication effect; the coefficient of friction decreases exponentially as the water film thickness increases [2, 18]. Also, the thicker water film causes a higher degree of hydroplaning, and thus threatens the safety during driving. Hydroplaning is a complex phenomenon that depends on several parameters such as water depth, vehicle speed, macrotexture of pavement, tire tread depth, tire inflation pressure, and contact area between tire and pavement [1]. The nano-lotus leaf coating might have a significant impact on the lubrication effect of water film thickness, thus on hydroplaning, because of its hydrophobicity. As a result, it could influence the safety of vehicles during driving on rigid pavements.

\subsection{Lotus leaf effect and sound absorption response}

According to Ashby et al. [6], any type of coating on a material surface, for instance a paint film, greatly reduces the noise absorption capacity of concrete or rigid pavements. The nano-lotus leaf coating is also expected to reduce the noise absorption of rigid pavements. However, the ability of the nano-lotus leaf coating to absorb noise needs to be explored.

\section{MATERIALS AND METHODS}

\subsection{Materials}

The materials used in the present study were generaluse (Type GU, formerly Type 10) Portland cement, fine and coarse aggregates, nano-lotus leaf solution products, polycarboxylate based high-range water reducer (HRWR), and air-entraining admixture (AEA). HRWR was used to achieve the target workability (slump), and AEA was used to achieve the target air content. Table 1 shows the gradation and key physical properties of fine and coarse aggregates.

Two different commercially available solution products of nano-lotus leaf were used to obtain thin coatings on the textured concrete surface of fabricated cylinder specimens. One of these two solution products was particularly formulated for use on concrete surface. Both nano-lotus leaf solution products were examined to evaluate their effects on the friction and sound absorption properties of rigid pavements. One of the two solution products provided better results that are reported in this article.

\subsection{Mix design and mix proportions}

The mix design of concrete was based on the procedure depicted in CSA A23.1-09/A23.2-09 [19]. 
Table 1. Gradation and physical properties of fine and coarse aggregates

\begin{tabular}{|c|c|c|c|}
\hline \multicolumn{4}{|c|}{ Gradation } \\
\hline \multicolumn{2}{|l|}{ Fine aggregate } & \multicolumn{2}{|l|}{ Coarse aggregate } \\
\hline \multirow{2}{*}{ Sieve size } & \multirow{2}{*}{$\%$ Passing } & Sieve size & $\%$ Passing \\
\hline & & $26.5 \mathrm{~mm}$ & 100 \\
\hline $4.75 \mathrm{~mm}$ & 99.8 & $22.4 \mathrm{~mm}$ & 99.2 \\
\hline $2.36 \mathrm{~mm}$ & 90.9 & $19 \mathrm{~mm}$ & 90.9 \\
\hline $1.18 \mathrm{~mm}$ & 68.6 & $16 \mathrm{~mm}$ & 70.5 \\
\hline $600 \mu \mathrm{m}$ & 47.1 & $13.2 \mathrm{~mm}$ & 54.7 \\
\hline $300 \mu \mathrm{m}$ & 21 & $9.5 \mathrm{~mm}$ & 31.3 \\
\hline $150 \mu \mathrm{m}$ & 6.8 & $6.7 \mathrm{~mm}$ & 13.7 \\
\hline $75 \mu \mathrm{m}$ & 2 & $4.75 \mathrm{~mm}$ & 6.2 \\
\hline \multicolumn{4}{|c|}{ Physical properties } \\
\hline \multicolumn{2}{|l|}{ Fine aggregate } & \multicolumn{2}{|l|}{ Coarse aggregate } \\
\hline Oven-dry based relative density & 2.671 & Oven-dry based relative density & 2.678 \\
\hline Saturated surface-dry based relative density & 2.705 & Saturated surface-dry based relative density & 2.709 \\
\hline Absorption & $1.20 \%$ & Absorption & $1.16 \%$ \\
\hline Fineness modulus & 2.7 & Oven-dry based bulk density & $1660 \mathrm{~kg} / \mathrm{m}^{3}$ \\
\hline
\end{tabular}

The following parameters were defined in the mix design: slump from $75 \mathrm{~mm}$ to $100 \mathrm{~mm}$, air content from $5 \%$ to $8 \%$ (tolerance: $\pm 1.5 \%$ ), $35 \mathrm{MPa}$ specified compressive strength at 28 days, Class $\mathrm{C}$-2 exposure, $43.5 \mathrm{MPa}$ design strength, and $20 \mathrm{~mm}$ nominal maximum size of coarse aggregate.

The weight based proportions of the concrete were as follows: $7.3 \%$ water, $21.2 \%$ cement, $44.8 \%$ coarse aggregate and $26.7 \%$ fine aggregate. The water to cement ratio (w/c) used in this study was 0.312 .

\subsection{Preparation of fresh concrete}

Concrete batches were produced in the laboratory using the mix proportions as depicted earlier in section 3.2. The constituent materials were mixed in a revolving pantype mixer to produce the concrete batches. The following mixing procedure was specifically used in this study:

- Coarse aggregate + fine aggregate + one-quarter of mixing water: mix for $1 \mathrm{~min}$;

- One-quarter of mixing water + AEA: mix for $1 \mathrm{~min}$;

- Cement + one-quarter of mixing water: mix for 3 $\min$;

- Covering the concrete within mixer pan with wet burlap: resting for $3 \mathrm{~min}$;

- One-quarter of mixing water + HRWR: mix for 3 min.

\subsection{Testing of fresh concrete}

After mixing, the fresh concrete batches were immediately tested for workability (slump), air content, and wet density following the procedures depicted in ASTM C143/C143M-10a [20], ASTM C231/C231M-10 [21], and ASTM C138/C138M-12 [22], respectively.

\subsection{Preparation of hardened test specimens}

One set of hardened test specimens were prepared from freshly mixed concrete batches. This set included three $100 \mathrm{~mm}$ (diameter) $\times 200 \mathrm{~mm}$ (height) cylinders for the compression test and fifteen $150 \mathrm{~mm}$ (diameter) $\times 75 \mathrm{~mm}$ (height) cylinders for friction and sound absorption tests. After molding, the top faces of the $150 \mathrm{~mm} \times 75 \mathrm{~mm}$ cylinders were finished by a broom to create macrotexture. All specimens were de-molded 24 hours after casting and then transferred to the fog room for wet curing. The visual inspection after casting and demolding was performed to ensure that the specimens had a similar macrotexture.

Nano-lotus leaf coatings were produced on the textured concrete surface by spraying the solution products. The coating was applied to twelve $150 \mathrm{~mm} \times 75 \mathrm{~mm}$ cylinder specimens; the textured surface of three cylinders of each set was not coated to obtain control specimens. Nano-lotus leaf solution was used in the following proportions: $0.0 \mathrm{~g} / \mathrm{m}^{2}$ (CC), $30 \mathrm{~g} / \mathrm{m}^{2}$ (NLLCC1), $60 \mathrm{~g} / \mathrm{m}^{2}$ (NLLCC2), $90 \mathrm{~g} / \mathrm{m}^{2}$ (NLLCC3) and $110 \mathrm{~g} / \mathrm{m}^{2}$ (NLLCC4) where CC means control concrete and NLLCC means nano-lotus leaf coated concrete. The nano-lotus leaf coatings were applied on 28 days old concrete. A coated concrete surface with lotus effect is shown in Fig. 1.

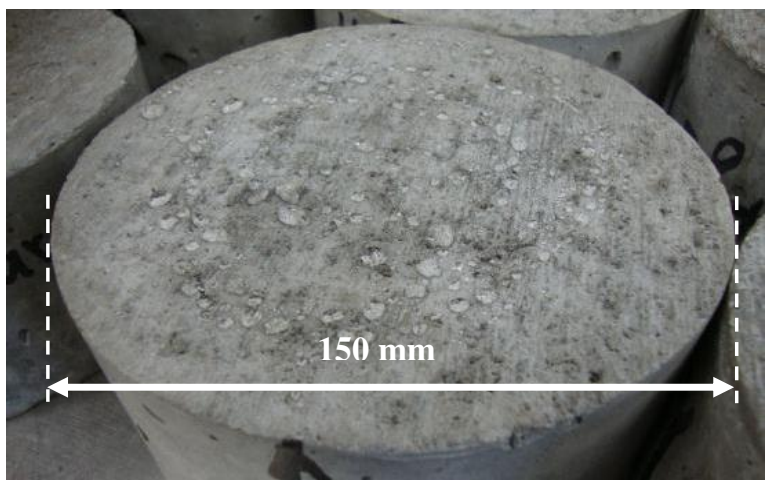

Fig. 1. Lotus effect on the coated surface of a concrete specimen

\subsection{Testing of hardened concrete specimens}

The hardened concrete specimens were tested for compressive strength, sound absorption, and friction at the 
age of 28 days. The compressive strength was determined using triplicate $100 \mathrm{~mm}$ (diameter) $\times 200 \mathrm{~mm}$ (height) cylinder specimens based on the procedure depicted in ASTM C39/C39M-12 [23].

The sound absorption coefficient was determined using all fifteen $150 \mathrm{~mm}$ (diameter) $\times 75 \mathrm{~mm}$ (height) concrete cylinders (12 coated and 3 uncoated specimens). The measurement for sound absorption was performed 24 hours after applying the coating. The sound absorption measurement was carried out in accordance with the procedure given in ASTM 1050-10 [24] using triplicate cylinders. An impedance tube, as shown in Fig. 2, was used to determine sound absorption coefficient. The tube was isolated in a soundproof chamber to avoid any external noise perturbation.

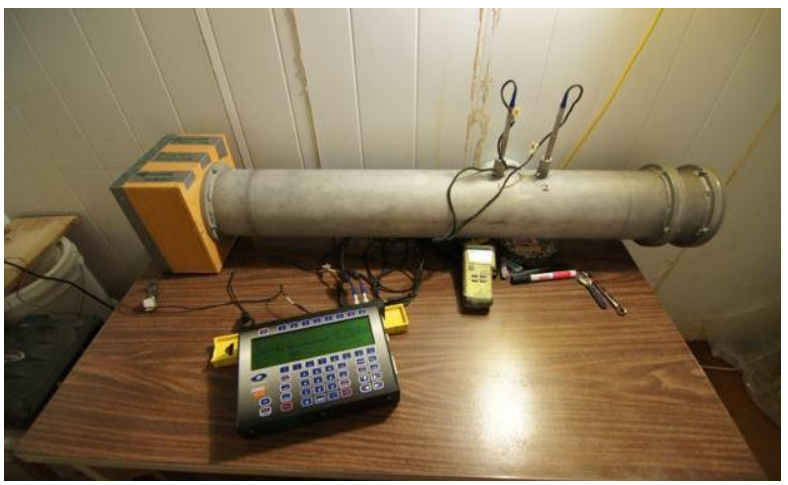

Fig. 2. Impedance tube test for sound absorption of concrete surface

After the sound absorption test, the same set of cylinder specimens was used to determine the friction value or skid resistance of coated and uncoated concrete surfaces. The friction property of concrete surfaces was measured in accordance with ASTM E303-93 [25] using the British pendulum tester, as shown in Fig. 3. In the British pendulum test, the concrete specimens were first positioned accordingly to simulate transverse finishing and then the measurement was performed in both dry and wet conditions. The measured friction values were corrected considering the difference between recorded and standard temperatures.

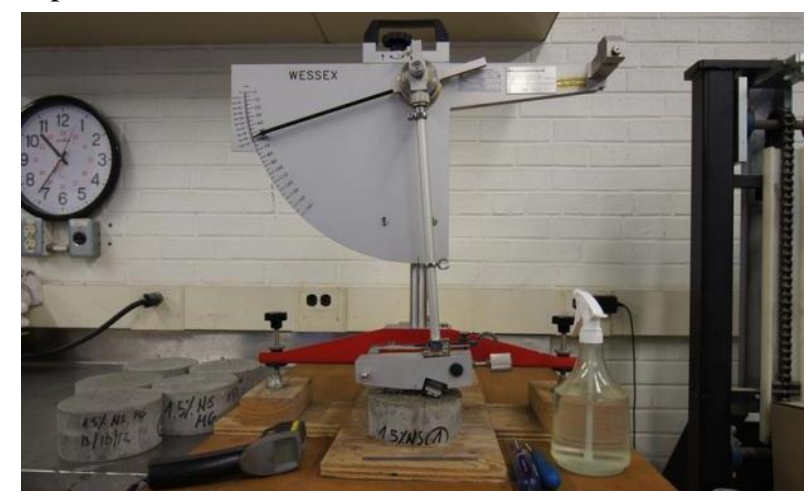

Fig. 3. British pendulum tester for friction property of concrete surface

\section{RESULTS AND DISCUSSION}

\subsection{Properties of fresh concrete}

The fresh concrete prepared had the properties presented in Table 2 . The workability and air content of the concrete mixture were within the intended ranges (refer to section 3.2).

Table 2. Fresh properties of concrete used in different tests

\begin{tabular}{|c|c|c|c|c|}
\hline $\begin{array}{c}\text { Slump, } \\
\mathrm{mm}\end{array}$ & $\begin{array}{c}\text { Air } \\
\text { content, } \%\end{array}$ & $\begin{array}{c}\text { Wet density, } \\
\mathrm{kg} / \mathrm{m}^{3}\end{array}$ & $\begin{array}{c}\mathrm{AEA}, \\
\mathrm{ml} / \mathrm{m}^{3}\end{array}$ & $\begin{array}{c}\mathrm{HRWR}, \\
\mathrm{ml}^{3} \mathrm{~m}^{3}\end{array}$ \\
\hline 70 & 4.5 & 2422 & 597 & 4377 \\
\hline \multicolumn{5}{|l}{ AEA: Air entraining admixture; } \\
HRWR: High-range water reducer. \\
HRW
\end{tabular}

\subsection{Properties of hardened concretes}

\subsubsection{Compressive strength}

The average compressive strength of the concrete was $68 \mathrm{MPa}$. The strength achieved can be considered reasonable for the w/c ratio of 0.312 , which was used in preparing the concrete mixture.

\subsubsection{Friction property}

The average results for the corrected friction value, represented as the British pendulum number (BPN), are shown in Fig. 4. The friction measurement was performed 24 hours after applying the coating on 28 days old concrete; the BPN was recorded in both dry and wet conditions. Test results presented in Fig. 4 shows that the coating was able to retain the friction property of concrete surface in both dry and wet conditions. However, it should be mentioned that the effect of nano-lotus leaf coating on the frictional response of uncoated and coated concrete surfaces in the presence of different water film thicknesses was not investigated in the present study. Only one water film thickness was considered in this study following ASTM E303-93 [25] to examine the effect of wetness on surface friction. Therefore, the ability of nano-lotus leaf coating to reduce hydroplaning during heavy rainfall remained unexplored.

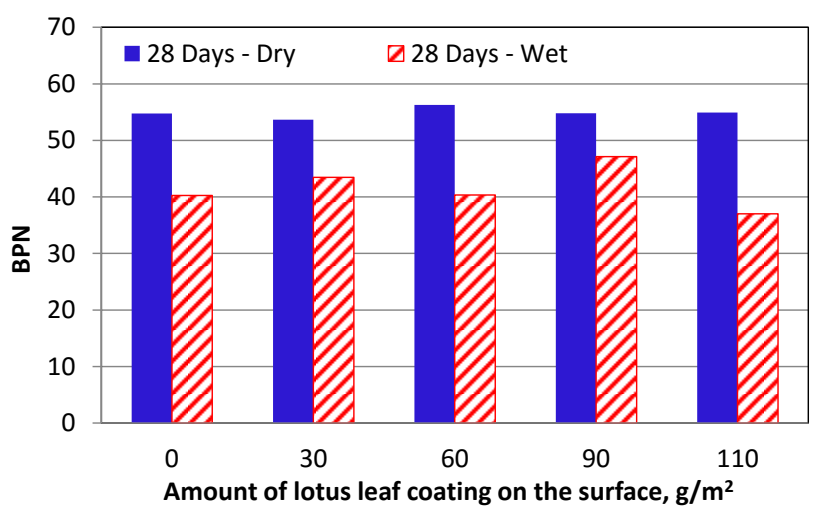

Fig. 4. Corrected British pendulum number (BPN) for coated and uncoated concrete surfaces in dry and wet conditions

\subsubsection{Sound absorption}

The sound absorption spectra of coated and uncoated concrete surfaces for the frequencies between 200 and $1200 \mathrm{~Hz}$ are presented in Fig. 5. For each curve, the data include the average from three specimens. Fig. 5 implies that the sound absorption coefficient in the frequency range of 900 to $1200 \mathrm{~Hz}$ varied insignificantly. This finding suggests that the sound waves were not affected by the nano-geometry of lotus leaf coating. The wavelength of sound ranges from $3.4 \mathrm{~m}$ to $0.34 \mathrm{~m}$ at 100 to $1000 \mathrm{~Hz}$ frequency [26]. According to Santamarina and Fratta [27], 
low-frequency waves are not affected by the small objects whereas the large objects affect both low- and highfrequency waves.

The maximum sound absorption coefficients for the frequencies in the range of $200-1200 \mathrm{~Hz}$ were also obtained from Fig. 5. These results are presented in Fig. 6. Despite some variations in the maximum value, the impact of the nano-lotus leaf coating on sound absorption was insignificant. This suggests that the coating did not significantly affect the sound absorption of concrete surface.

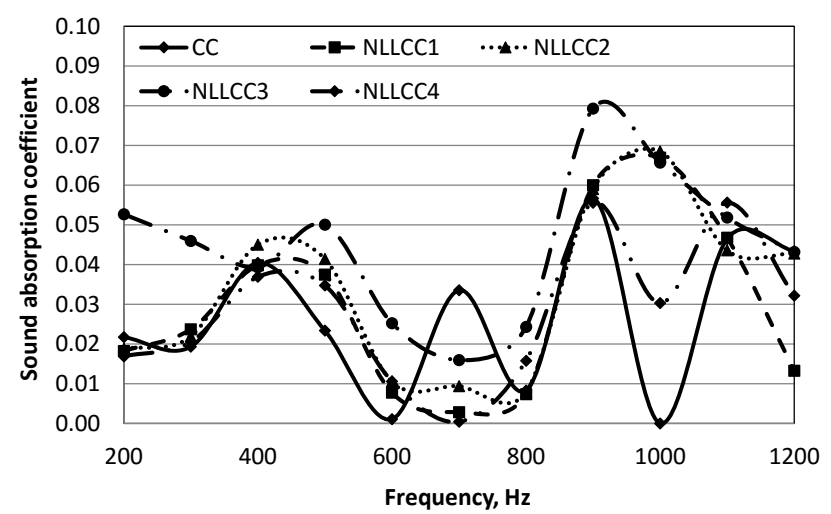

Fig. 5. Average sound absorption spectra of 28-day old uncoated and coated concrete surfaces

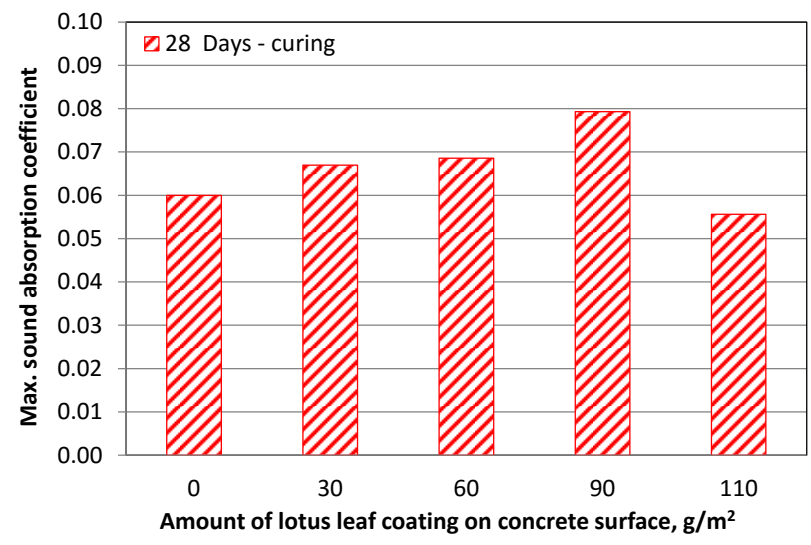

Fig. 6. Maximum sound absorption coefficient for 28-day old uncoated and coated concrete surfaces

\subsubsection{Statistical analysis}

Table 3. Results of statistical analysis for compressive strength, wet friction, and sound absorption

\begin{tabular}{|c|c|c|c|c|}
\hline Type of concrete & Hardened concrete properties & Mean & SD & $\mathrm{COV}, \%$ \\
\hline Control concrete $(\mathrm{CC})$ & Compressive strength $(\mathrm{MPa})$ & 67.5 & 3.0 & 4.4 \\
\hline $\mathrm{CC}\left(0.0 \mathrm{~g} / \mathrm{m}^{2}\right)$ & \multirow{5}{*}{$\begin{array}{l}\text { British pendulum number (BPN) } \\
\text { in wet condition }\end{array}$} & 40.3 & 5.2 & 12.8 \\
\hline $\operatorname{NLLCC} 1\left(30 \mathrm{~g} / \mathrm{m}^{2}\right)$ & & 43.4 & 5.9 & 13.6 \\
\hline $\operatorname{NLLCC} 2\left(60 \mathrm{~g} / \mathrm{m}^{2}\right)$ & & 40.4 & 5.7 & 14.2 \\
\hline $\operatorname{NLLCC} 3\left(90 \mathrm{~g} / \mathrm{m}^{2}\right)$ & & 47.1 & 2.7 & 5.8 \\
\hline NLLCC4 $\left(110 \mathrm{~g} / \mathrm{m}^{2}\right)$ & & 37.0 & 6.4 & 17.2 \\
\hline $\mathrm{CC}\left(0.0 \mathrm{~g} / \mathrm{m}^{2}\right)$ & \multirow{5}{*}{ Sound absorption coefficient } & 0.06 & 0.01 & 9.7 \\
\hline $\operatorname{NLLCC} 1\left(30 \mathrm{~g} / \mathrm{m}^{2}\right)$ & & 0.07 & 0.01 & 16.7 \\
\hline $\operatorname{NLLCC} 2\left(60 \mathrm{~g} / \mathrm{m}^{2}\right)$ & & 0.07 & 0.01 & 12.2 \\
\hline NLLCC3 $\left(90 \mathrm{~g} / \mathrm{m}^{2}\right)$ & & 0.08 & 0.01 & 8.9 \\
\hline NLLCC4 $\left(110 \mathrm{~g} / \mathrm{m}^{2}\right)$ & & 0.06 & 0.01 & 19.1 \\
\hline
\end{tabular}

The statistical analysis was carried out for compressive strength, friction, and sound absorption properties. Table 3 shows the results of the statistical analysis. The standard deviation and coefficient of variation obtained for compressive strength and wet friction values indicated that both properties have acceptable variations. The results of sound absorption were also consistent with previous studies [4]; however, the coefficient of variation slightly increased for this property. This is because the mean values of sound absorption coefficient were significantly lower than those of compressive strength and friction value. Therefore, a small variation in sound absorption may produce a significant impact on the coefficient of variation.

\section{CONCLUSIONS}

Based on the findings of this study, the following conclusions are drawn:

- The lotus leaf effect on concrete surface can be mimicked by applying a surface coating.

- Nano-lotus leaf coating can maintain the required friction property of broom finished concrete, as observed from the results of British pendulum test.

- The laboratory data make it clear that an appropriate nano-lotus leaf coating produces no significant impact on the sound absorption of concrete.

- Further research must be carried out to verify the ability of nano-lotus leaf coating to retain or improve the friction property of rigid pavement and reduce hydroplaning during heavy rainfall.

\section{Acknowledgements}

The authors acknowledge the support and contribution of the Cement Association of Canada (CAC), particularly Rico Fung who is the Director of CAC's Markets and Technical Affairs in Ontario. In addition, the authors are grateful to BASF Canada and St Mary's Cement for the supply of chemical admixtures and cement used in the present study. The authors are also thankful to Undergraduate Research Assistant Yulei Huang for her assistance in editing the article. 


\section{REFERENCES}

1. Hall, J. W., Smith, K. L., Littleton, P. C. Texturing of Concrete Pavements. Transportation Research Board of the National Academies, Washington D.C., USA, 2009.

2. Hall, J. W., $\quad$ Smith, K. L., Titus-Glover, L., Wambold, J. C., Yager, T. J., Rado, Z. Guide for Pavement Friction. Transportation Research Board of the National Academies, Washington D.C., USA, 2009.

3. Scofield, L. Development and Implementation of the Next Generation Concrete Surface. American Concrete Pavement Association (ACPA), Washington D.C., USA, 2011.

4. Gonzalez, M., Safiuddin, M., Cao, J., Tighe, S. L. Sound Absorption and Friction Responses of Nano-concrete for Rigid Pavements Transportation Research Record 2369 2013: pp. $87-94$. http://dx.doi.org/10.3141/2369-1

5. Button, J., Emmanuel, F., Middleton, R. Synthesis of Pavement Issues Related to High-Speed Corridors. Texas Transportation Institute, Texas, USA, 2004.

6. Ashby, M., Ferreira, P., Schodek, D. Nanomaterials, Nanotechnologies and Design: An Introduction for Engineers and Architects. Elsevier Science Ltd., Massachusetts, USA, 2009.

7. Rana, A. K., $\quad$ Rana, S. B., Kuman, A., Kiran, V. Significance of Nanotechnology in Construction Engineering International Journal of Recent Trends in Engineering 1 (4) 2009: pp. 46-48. http://dx.doi.org/academypublisher.com/ijrte/vol01/no04/ijrte0104046048.pdf

8. Mann, S. Nanotechnology and Construction. Institute of Nanotechnology, Scotland, UK, 2006.

9. Sobolev, K., Flores, I., Hermosillo, R., TorresMartínez, L. M. Nanomaterials and Nanotechnology for High-Performance Cement Composites Proceedings of ACI Sessions on Nanotechnology of Concrete: Recent Developments and Future Perspectives 2006: pp. 91-118. http://dx.doi.org/10.14359/20213

10. Raki, L., Beaudoin, J., Alizadeh, R., Makar, J., Sato, T. Cement and Concrete Nanoscience and Nanotechnology Materials 3 (2) 2010: pp. 918-942.

doi: 10.3390/ma3020918

11. Sanchez, F., Sobolev, K. Nanotechnology in Concrete - A review Construction and Building Materials 24 2010: pp. 2060-2071. http://dx.doi.org/10.1016/j.conbuildmat.2010.03.014

12. Balaguru, P., Chong, K. Nanotechnology and Concrete Research Opportunities Proceedings. of ACI Sessions on Nanotechnology of Concrete: Recent Developments and Future Perspectives 2006: pp. 15-28. http://dx.doi.org/10.14359/20208

13. Sobolev, K., Gutierrez, M. F. How Nanotechnology Can Change the Concrete World American Ceramic Society Bulletin 84 (11) 2005: pp. 16-19. http://dx.doi.org/10.1002/9780470588260.ch16
14. Kumar, V. R., Bhuvaneshwari, B., Maheswaran, S., Palani, G. S., Ravisankar, K., Iyer, N. R. An Overview of Techniques based on Biomimetics for Sustainable Development of Concrete Current Science 101 (6) 2011: pp. $741-747$. ttp://dx.doi.org/101/06/0741

15. Mozumder, M. S., Zhang, H., Zhu, J. Mimicking Lotus Leaf: Development of Micro-Nanostructured Biomimetic Superhydrophobic Polymeric Surfaces by Ultrafine Powder Coating Technology Macromolecular Materials and Engineering 296 (10) 2011: pp. 929-936.

http://dx.doi.org/10.1002/mame.201100080

16. Su, C. Facile Fabrication of a Lotus-effect Composite Coating via Wrapping Silica with Polyurethane Applied Surface Science 256 2010: pp. 2122-2127. ttp://dx.doi.org/10.1016/j.apsusc.2009.09.058

17. Forbes, P. Self-cleaning Materials: Lotus Leaf-Inspired Nanotechnology Scientific American 2008: pp. 1-5. http://dx.doi.org/10.1038/scientificamerican0808-88

18. Henry, J. J. Evaluation of Pavement Friction Characteristics. Transportation Research Board of the National Academies, Washington D.C., USA, 2000.

19. CSA A23.1-09/A23.2-09. Concrete Materials and Methods of Concrete Construction/Test Methods and Standard Practices for Concrete. Canadian Standard Association, Mississauga, Ontario, Canada, 2009.

20. ASTM C143/C143M-10a. Standard Test Method for Slump of Hydraulic-Cement Concrete. ASTM International, Philadelphia, USA, 2010.

21. ASTM C231/C231M-10. Standard Test Method for Air Content of Freshly Mixed Concrete by the Pressure Method. ASTM International, Philadelphia, USA, 2010.

22. ASTM C138/C138M-12. Standard Test Method for Density (Unit Weight), Yield, and Air Content (Gravimetric) of Concrete. ASTM International, Philadelphia, USA, 2012.

23. ASTM C39/C39M-12. Standard Test Method for Compressive Strength of Cylindrical Concrete Specimens. ASTM International, Philadelphia, USA, 2012.

24. ASTM E1050-10. Standard Test Method for Impedance and Absorption of Acoustical Materials Using a Tube, Two Microphones and a Digital Frequency Analysis System. ASTM International, Philadelphia, USA, 2010.

25. ASTM E303-93 (Reapproved 2008). Standard Test Method for Measuring Surface Frictional Properties Using the British Pendulum Tester. ASTM International, Philadelphia, USA, 2008.

26. Bernhard, R., Wayson, R. L. An Introduction of Tire/Pavement Noise of Asphalt Pavement. http://www.quietpavement.com, accessed on October 2011.

27. Santamarina, C., Fratta, D. Introduction to Discrete Signals and Inverse Problems in Civil Engineering. ASCE Press, American Society of Civil Engineers, Virginia, USA, 1998. 